\title{
Extraction and Viability Checking of Various Carbonated Hydroxyapatite by Wharton's Jelly Mesenchymal Stem Cell
}

\author{
${ }^{1}$ Abbas Fazel Anvari-Yazdi, ${ }^{2}$ Arash Yazdani, ${ }^{3}$ Tahereh Talaei-Khozani and ${ }^{1}$ Mahdi Kalantar \\ ${ }^{1}$ Research and Development (R \& D) in Material Engineering, Innovation Center, Yazd Science and Technology \\ Park, Yazd, Iran \\ ${ }^{2}$ Faculty of Materials Engineering, Shahrood University of Technology, Shahrood, Iran \\ ${ }^{3}$ Department of Tissue Engineering, Shiraz University of Medical Sciences, Shiraz, Iran
}

\begin{abstract}
In this study, new approaches are used to culture Wharton's Jelly Mesenchymal Stem Cells (WJ-MSCs) on 2-Dimensional carbonated hydroxyapatite (CHAp) scaffolds extracted from bio-waste of bovine bones. To extract CHAp bioceramics, three different methods have been applied to achieve pure natural CHAp: Thermal Calcination (at temperature of $700^{\circ} \mathrm{C}$ ), alkaline hydrothermal $\left(275^{\circ} \mathrm{C}\right)$ and aqueous hydrothermal $\left(250^{\circ} \mathrm{C}\right)$. Raw bovine bone and obtained apatites have been characterized by X-ray Diffraction (XRD) and Fourier-transform infrared spectroscopy (FT-IR). The FT-IR spectrums indicated that all of the utilized processes have the ability of plucking collagen and other organic compounds out of bovine bones and finally leaving pure natural CHAp with yield of $\sim 60 \%$. Fluorescent Microscopy and Scanning Electron Microscopy (SEM) were used to evaluate WJ-MSCs growth behavior, Viability and adhesion of Cells on the surface of 2-D hydroxyapatite scaffolds derived by these three different methods. In these processes, obtained apatites leave carbonate contents in specific temperatures which leads to increased biological effects in derived CHAp and preferable for orthopedic and medical usages. The findings suggest that WJ-MSCs could survive and attach onto these scaffolds and demonstrate no negative response to carbonated hydroxyapatite.
\end{abstract}

Key words: Wharton's Jelly, mesenchymal, stem cell, hydroxyapatites, bovine bone, flowcytometery, physiochemical characterization, scaffold, bio-waste

Science International, 1 (5): 132-138, 2013

\section{INTRODUCTION}

Ceramic materials have been part of everyday life for thousands of years. Hydroxyapatite (HAp) or calcium phosphates are the major constituents of bone minerals. The most extensively used synthetic calcium phosphate ceramic for bone replacement is HAp because of the chemical similarities to the inorganic component of bone and teeth. HAp with the chemical formula of $\mathrm{Ca}_{10}$ $\left(\mathrm{PO}_{4}\right)_{6}(\mathrm{OH})_{2}$ has a theoretical composition of $\mathrm{Ca} / \mathrm{P}$ molar ratio of 1.667. Most clinical application of bioceramic relate to the repair of the skeletal system, comprising bone, joints and teeth and to augment hard tissue ${ }^{1}$.

In bone tissue surgery although autografts are still the most preferred to replace human bone tissue, other alternatives are commonly used to overcome its limitation to supply and the requisite of additional surgery ${ }^{2}$. The alternatives substitution bone graft can be xenograft, allograft and synthetic or commercial biomaterials ${ }^{3,4,5}$. The synthetic calcium phosphates composites are differ from apatites extracted from natural

Corresponding Author: Abbas Fazel Anvari-Yazdi, Research and Development ( $\&$ \&) in Material Engineering, Innovation Center, Yazd Science and Technology Park, Yazd, Iran materials such as bone; due to absence of other mineral components existed in the bone. Therefore, the synthetic calcium phosphates composite cannot mimic real hydroxyapatite crystals of a bone ${ }^{6}$. As the matter of fact, natural apatites are non-stoichiometric $(\mathrm{Ca} / \mathrm{P}$ molar ratio over 1.67) and contain carbonate groups $\left(\mathrm{CO}_{3}\right)$ and usually partial bioactive ions (e.g. $\mathrm{Mg}, \mathrm{Na}, \mathrm{K}, \mathrm{Si}$, etc.) which localized interstitially and substitutionaly into its structure, respectively. Carbonate groups are the most abundant substitution in bone minerals and might be found in two types of $\mathrm{A}(\mathrm{OH}-)$ and $\mathrm{B}\left(\mathrm{PO}_{4}{ }^{3-}\right)$. Amount of $\mathrm{B}$ type carbonate being the most frequent in natural bones like human skeleton ${ }^{5,7,8,9}$. However, the amount of these ions is very low, but plays a vital role in the biological reactions associated with bone metabolism ${ }^{10}$ during the life of bone growth. One strategy to improve non-autograft materials while maintaining their advantages regarding their chemical and physical properties is to produce them from natural sources (e.g. fish bone, bovine bone, teeth, etc.). The traditional heat treatment calcination ${ }^{10,11,12,13,14}$, novel techniques of alkaline hydrothermal $(\mathrm{NaOH})$ and aqueous hydrothermal (PLPW) could be maintains these traits ${ }^{15}$. Natural apatites 
obtained by these techniques have the advantages of inheriting the chemical composition and structure of the raw material, being thus alternative solution for numerous applications based on its analogues synthetic products. As compared to allogeneic bone, obtained carbonated hydroxyapatite from xenogeneic bone (generally bovine bones) is considered a good choice due to its lower cost, available in unlimited supply and it is easier to obtain (economically cheaper and environmentally preferable) ${ }^{16}$.

In biologic conditions, a cell interrogates and signals to its local environment using surface interactions. Within any tissue the massive combined surface area of component cells results in an immense number of specific molecular interactions between cell membrane components and Extracellular Matrix (ECM). One of the central functions of a tissue engineering scaffold is to mimic the ECM. Therefore, the nature of the interfacial relationship between cells and scaffolds is of great importance $^{17}$.

Skeletal tissues originate mostly from mesenchymal stem cells during embryonic development. In the adult stage, mesenchymal stem cells can be isolated from bone marrow, adipose tissues, amniotic membrane or umbilical cord perivascular tissue. Mesenchymal stem cells are, by definition, of self-renewal capacity to repopulate the entire appropriate cell lineage. They are multi potential cells that can differentiate into osteoblastic, myoblastic, adipogenic chondrogenic, endothelial and neurogenic lineage through a multistep differentiation sequence as follows: proliferation, commitment, lineage progression, differentiation and maturation. Regarding bone tissue, its formation takes place in an organism during (i) Embryonic development, (ii) Growth, (iii) Remodeling, (iv) Fracture healing and (v) After ectopic implantation of osteoinductive matrices. Additionally, a mineral phase synthesized under similar physiological conditions to bone mineral might confer to the ceramic a reactivity that could positively influence cells and hosting tissues in favor to new formation ${ }^{18}$.

The present study focuses on the study of preparing and extraction of HCAp directly from bovine bone through three various methods: (i) Alkaline $(\mathrm{NaOH})$, (ii) Pressurized Low Polarity Water (PLPW) and (iii) Calcination treatment to obtain carbonated hydroxyapatites for medical applications. Mesenchymal stem cell which has been derived from an umbilical cord tissue that named Wharton's Jelly, has used for biocompatibility studies of 2-D scaffolds of carbonated hydroxyapatite prepared for bone tissue repair in vitro.

\section{MATERIALS AND METHODS}

Isolation and culture of mesenchymal stem cell: Mesenchymal stem cell isolated from cord tissue of the infants delivered by cesarean section with informed parental consent. Umbilical cord vein were flashed by Phosphate Buffer Saline (PBS) to remove the blood clots. The umbilical arteries were removed and the rest was minced into small pieces. The pieces were explanted in culture dishes and cultured for 10 days in DMEM containing 1\% L-glutamine and $1 \%$ penicillin/Streptomycin. After separating the pieces of tissue from the floor of culture plate, the cells were harvested by trypsin/EDTA and subcultured into a culture flask. The cells at the passage 3 were established by detecting CD markers. FITC-conjugated anti-CD44, anti-CD90 and CD144 antibody, PerCP-conjugated anti-CD105, PE-conjugated CD106 and PE-conjugated anti-CD34 antibody (all from Abcam, UK, Cambridge) were used to detect the CD markers. The percentages of positive cells were assayed by flow cytometry ${ }^{19}$.

Bovine bone preparation: The fresh adult bovine bones (2 years-male) were used as raw materials. In the beginning, the thigh is broken and the inside fats and spongy parts were removed from compacted parts. Then it was cut into $1 \times 1 \times 1 \mathrm{~cm}$ pieces and boiled in distilled water for 2-3 h until the fats and impurities on the surface removed. In next step, the samples immersed in acetone (Merck- $\mathrm{CH}_{3} \mathrm{COCH}_{3}$ ) solution and maintained 36 hours at temperature of "between" $4-6^{\circ} \mathrm{C}$ to dissolve remained fats on the surface of bone. Afterwards, the samples have been dried at $150^{\circ} \mathrm{C}$ for $48 \mathrm{~h}$ in oven to remove incorporated water. Finally the samples grinded by fast mill to particle size less than 10 micrometer (Table 1).

Alkaline hydrothermal treatment: In this process, cylindrical S.S. autoclave with dimensions of $100 \mathrm{~mm}$ height and $90 \mathrm{~mm}$ diameter was used as a reactor. Sodium hydroxide ( $\mathrm{NaOH}>97 \%$ purity) (Merck-AG Darmstadt, Germany) was utilized for decomposition and hydrolysis of collagen and organic components. Raw bovine bone powders were mixed with the $45 \mathrm{wt} . \% \mathrm{NaOH}$ solution with solid/liquid ratio of $1: 30$ and heated at $275^{\circ} \mathrm{C}$ for $4 \mathrm{~h}$ in autoclave ${ }^{15}$.

Aqueous hydrothermal treatment: In this process, grinded powders were added to deionized water with solid/liquid ratio of $1: 50$ at $250^{\circ} \mathrm{C}$ for $2 \mathrm{~h}$. All the same aforementioned levels were utilized by autoclave in this technique $^{15}$.

\begin{tabular}{|c|c|c|}
\hline Type of process & Crystallinity $\mathrm{X}_{C}(\%)$ & Temperature $\left({ }^{\circ} \mathrm{C}\right)$ \\
\hline Calcination & 57.0 & 700 \\
\hline $\mathrm{NaOH}$ & 22.0 & 275 \\
\hline PLPW & 6.0 & 200 \\
\hline Raw bone & 0.9 & 37 \\
\hline
\end{tabular}


Calcinations treatment: In the thermal calcination process, the amount of $10 \mathrm{~g}$ grinded powder of raw material placed in refractory plate and then was heated by Nabertherm ${ }^{\oplus}$ electric furnace under ambient air atmosphere by heating rate of $10^{\circ} \mathrm{C} \mathrm{min}{ }^{-1}$ from $30^{\circ} \mathrm{C}$ to $700^{\circ} \mathrm{C}$. The powder kept for 6 hours at $700^{\circ} \mathrm{C}$ and subsequently cooled to room temperature. The whole process lasted $24 \mathrm{~h}$.

Preparation of 2-D scaffolds: To culture the stem cells, the obtained powders from three different methods have been produced as a pellet with dimensions of $10 \mathrm{~mm}$ in diameter and $2 \mathrm{~mm}$ in thickness. The powders were mixed by $50 \%$ Poly-vinyl Alcohol (PVA) and deionized water. The powders were dried and shaped by Cold Isostatic Pressing (CIP) technique with pressure of $30 \mathrm{bar}$ and finally aged for $36 \mathrm{~h}$ at temperature of $200^{\circ} \mathrm{C}$.

Culturing of stem cells on 2-D scaffolds: The $12.5 \times 10^{4}$ cells were cultured on each scaffold in the presence of DMEM containing 10\% FCS, $1 \% \mathrm{~L}$-glutamine and $1 \%$ penicillin/Streptomycin for $24 \mathrm{~h}$. To evaluate the cells on the scaffolds, the cultures were fixed with $4 \%$ paraformaldehyde and they were washed with PBS and immersed in $10 \mathrm{ng} \mathrm{mL}^{-1}$ DAPI $\left(\mathrm{C}_{16} \mathrm{H}_{15} \mathrm{~N}_{5}\right.$-Sigma Aldrich) for $5 \mathrm{~min}$. Finally the scaffolds were washed and observed under a fluorescence microscopy.

Powders and sample characterizations: To investigate the functional groups in powders, organic compounds, hydroxyl groups $\left(\mathrm{OH}^{-}\right)$, carbonate $\left(\mathrm{CO}_{3}{ }^{2-}\right)$ and anion phosphate $\left(\mathrm{PO}_{4} 3^{-}\right)$, the Fourier-transform infrared spectroscopy (FT-IR_Bruker Tensor 27, ATR, Germany) was used to investigate the chemical composition of raw bone and treated bones. The spectrum was recorded between 400 and $4000 \mathrm{~cm}^{-1}$. For this measurement, the absorbance IR spectra were recorded using $\mathrm{KBr}$ (Merck) pellets (3 mg sample and $300 \mathrm{mg} \mathrm{KBr}$ ).

$\mathrm{X}$-ray Diffraction (XRD) was used to characterize the chemical composition and structure of the materials before and after treatments at room temperature, with Philips X'Pert-MPD (Philips, Amsterdam, Netherland) using $\mathrm{CuK}_{\hat{a}}(\lambda=0.15405 \mathrm{~nm})$ radiation source at $30 \mathrm{~mA}$, $40 \mathrm{kV}$. Scans speed were performed with $(2 \theta / \mathrm{S}) 0.05 \% / \mathrm{sec}$ and $2 \theta$ values from 20 to $60^{\circ}$. The phase composition and crystalline phase compositions of the powders was monitored by comparing acquired spectrums with peaks identified in the Joint Committee on Powder Diffraction Standards (JCPDS_4-697) database standard or ICDD cards available in the system software ${ }^{20}$.

To detect the morphology and structure of cultured stem cells, scanning electron microscopy (SEM-VEGAITESCAN-LMU) were used. Also, fluorescence microscope (Nikon-Eclipse E600W) was utilized to assay the viability and growth of stem cells on each scaffold.

\section{RESULTS AND DISCUSSION}

FT-IR analysis: The bovine bone is an extracellular matrix mainly constituted by calcium phosphates nano-crystals and collagen fibers ${ }^{15}$. FT-IR spectroscopy is one of the best tools for structural investigations of organic and inorganic compounds and reveals significant amounts of structural carbonate in all four samples. The spectrums of raw bovine bone and treated bones are shown in Fig. 1. In FT-IR spectra absorptions, amorphous contents and associated minerals were detected in this technique.

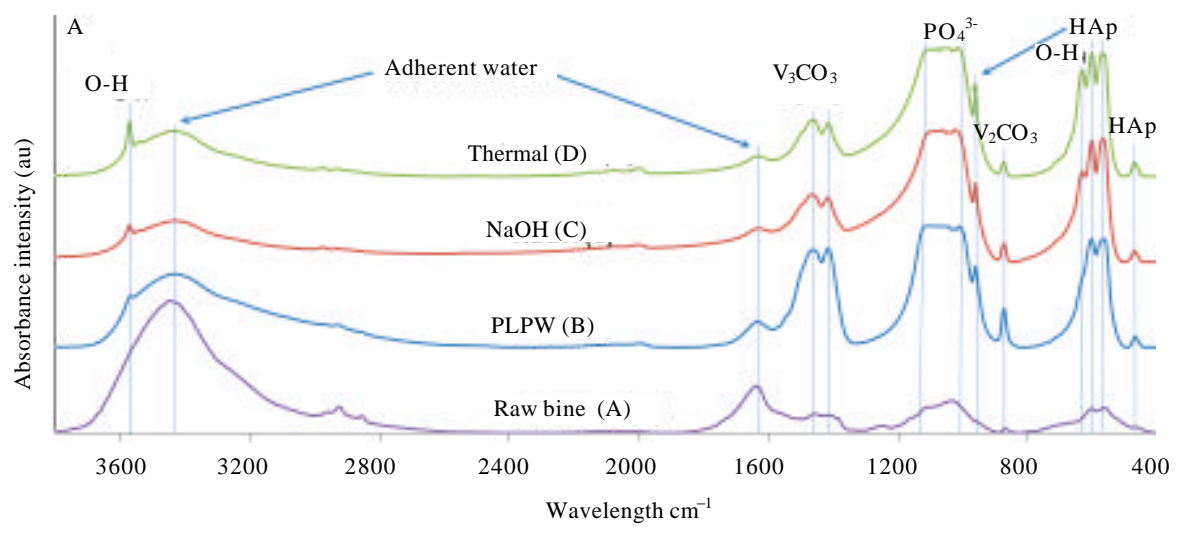

Fig. 1: FT-IR spectrums of obtained HCAp from bovine bone accompanying hydroxyl, phosphate and carbonate vibration; (A) Raw bone, (B) PLPW, (C) NaOH, (D) Thermal-700 ${ }^{\circ} \mathrm{C}$ 
Figure 2a Shows the absorption bands of collagen vibration namely at 1222 to $1394 \mathrm{~cm}^{-1}$. These spectrums after proposed three treatments disappeared and indicate that all organic compounds have been removed from bovine bone powders (Fig. 2b). It was reported that, almost all bands of hydroxyl $(\mathrm{O}-\mathrm{H})$, phosphate and apatites increased in intensity by increasing of treatment temperature; but the intensity of adherent water (1647 and $3450 \mathrm{~cm}^{-1}$ ) decreased simultaneously. As expected, hydroxyl groups were identified in wavelength of 3570 and $638 \mathrm{~cm}^{-1[14]}$. It should be noticed that, the weak band observed in spectra of obtained HCAp at $638 \mathrm{~cm}^{-1}$ could not be identified in the spectra of raw bovine bone sample.

Additionally, the typical bands of substituted carbonates localized in sloping and vertical faces of the tetrahedron sites of phosphate (type B) in the apatite lattice. It appears that the carbonate ion can substitute for both $\mathrm{O}-\mathrm{H}$ in the $\mathrm{c}$-axis channel of apatite (type A carbonate) and phosphate group (type $\mathrm{B}$ carbonate). It is presently observed that type $\mathrm{B}$ carbonate is characterized by a single band at $871 \mathrm{~cm}^{-1}\left(\mathrm{v}_{22}, \mathrm{CO}_{3}\right)$ and double band at $1410 \mathrm{~cm}^{-1}$ and $1455 \mathrm{~cm}^{-1}$ associated to type A carbonate $\left(\mathrm{v}_{33}, \mathrm{CO}_{3}\right)^{21}$. Phosphate vibrations are detected in range of 1016 to $1126 \mathrm{~cm}^{-1}$ and vibrations at $476,576,607$ and $964 \mathrm{~cm}^{-1}$ are related to HAp mineral composition ${ }^{14}$.
XRD analysis: The XRD patterns of bovine bone and treated bone powders are shown in Fig. 3 within the range of $20^{\circ} \leq 2 \theta \leq 60^{\circ}$. $X$-ray diffraction method is
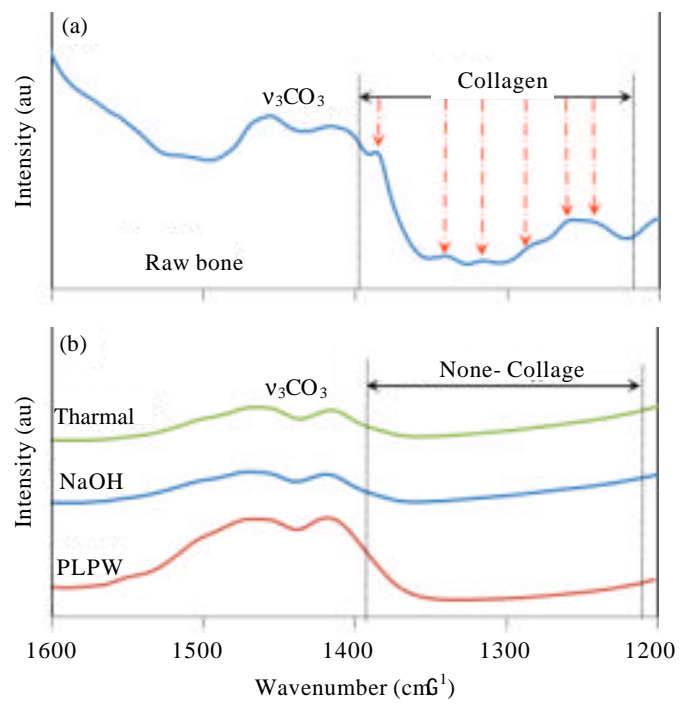

Fig. 2(a-b): (a) FT-IR spectrums of collagen vibration and (b) Treated bone by three different processes

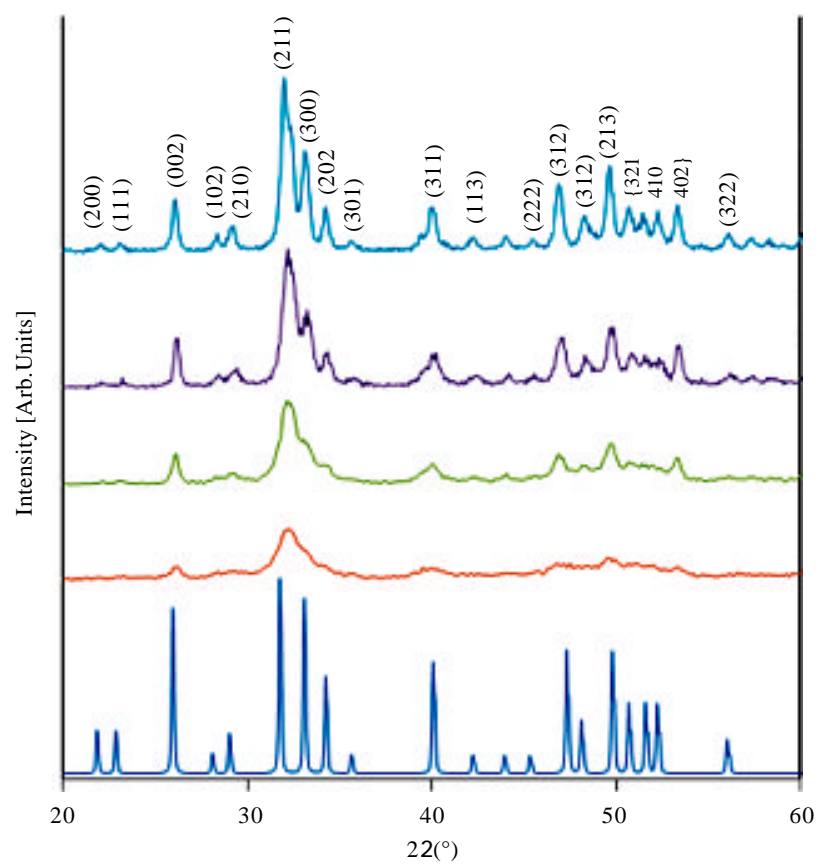

Fig. 3: Comparison of xRD patterns with JCPDS-4-697 and ciys +allographic 
employed to evaluate the structural changes and phase purity of obtained carbonated hydroxyapatites. The $\mathrm{X}$-ray diffractions indexed on basis of hexagonal crystal system (axis $\mathrm{a}=\mathrm{b}=\sim 0.93 \mathrm{~nm}$, axis $\mathrm{c}=\sim 0.68 \mathrm{~nm}$ and $\mathrm{Y}=120^{\circ}$ ) of space group of $\mathrm{P}_{3} / \mathrm{M}^{20}$. The main Bragg peaks according to JCPDS file No.4-697 observed at $26^{\circ}, 28^{\circ}, 29^{\circ}, 31^{\circ}, 33^{\circ}, 34^{\circ}, 35^{\circ}, 39^{\circ}, 41^{\circ}, 43^{\circ}, 45^{\circ}, 46^{\circ}$, $48^{\circ}, 49^{\circ}, 50^{\circ}, 51^{\circ}, 52^{\circ}$ and $56^{\circ}$. As shown in Fig. 3, the crystallinity of raw bovine bone is too low and has expanded peaks around $30^{\circ}-35^{\circ}$ and $46^{\circ}-56^{\circ}$. Two parameters can affect the low intensity and broad peaks of XRD patterns of bovine bone: (I) presence of collagen compounds in matrix of bone which disperses X-ray radiations, (ii) amorphous structure of bone.

Afterwards, by increasing of temperature from $250^{\circ} \mathrm{C}$ for PLPW, $275^{\circ} \mathrm{C}$ for $\mathrm{NaOH}$ and $700^{\circ} \mathrm{C}$ for thermal processes, the crystallinity of powders began to increased alternatively and main planes of HCAp appears with increasing the temperature. According to Pang equation ${ }^{22}$, the crystallinity degree of crystalline phases was calculated (Eq. 1).

$$
\mathrm{XC}=1-\left(\mathrm{V}_{112 / 300}\right) / \mathrm{I}_{300}
$$

where, $\mathrm{I}_{300}$ is the intensity of $(300)$ reflection and $V_{112 / 300}$ is the intensity of the hollow between (1 12 ) and (3 00 ) reflections.

In apatite lattice, due to presence of carbonate ions interstitially in structure, the planar spacing of tetrahedron phosphates increased and broadening of main peaks take place. It has reported that, at elevated temperature $\left(\right.$ e.g. $\left.700^{\circ} \mathrm{C}\right)$ the carbonate contents began to decompose in gaseous shape like $\mathrm{CO}_{2}{ }^{23}$.

Viability and flow cytometery checking: The flowcytometry showed that the $96.89,26.54$ and $39.22 \%$ of the cells expressed CD44, CD106 and CD105,
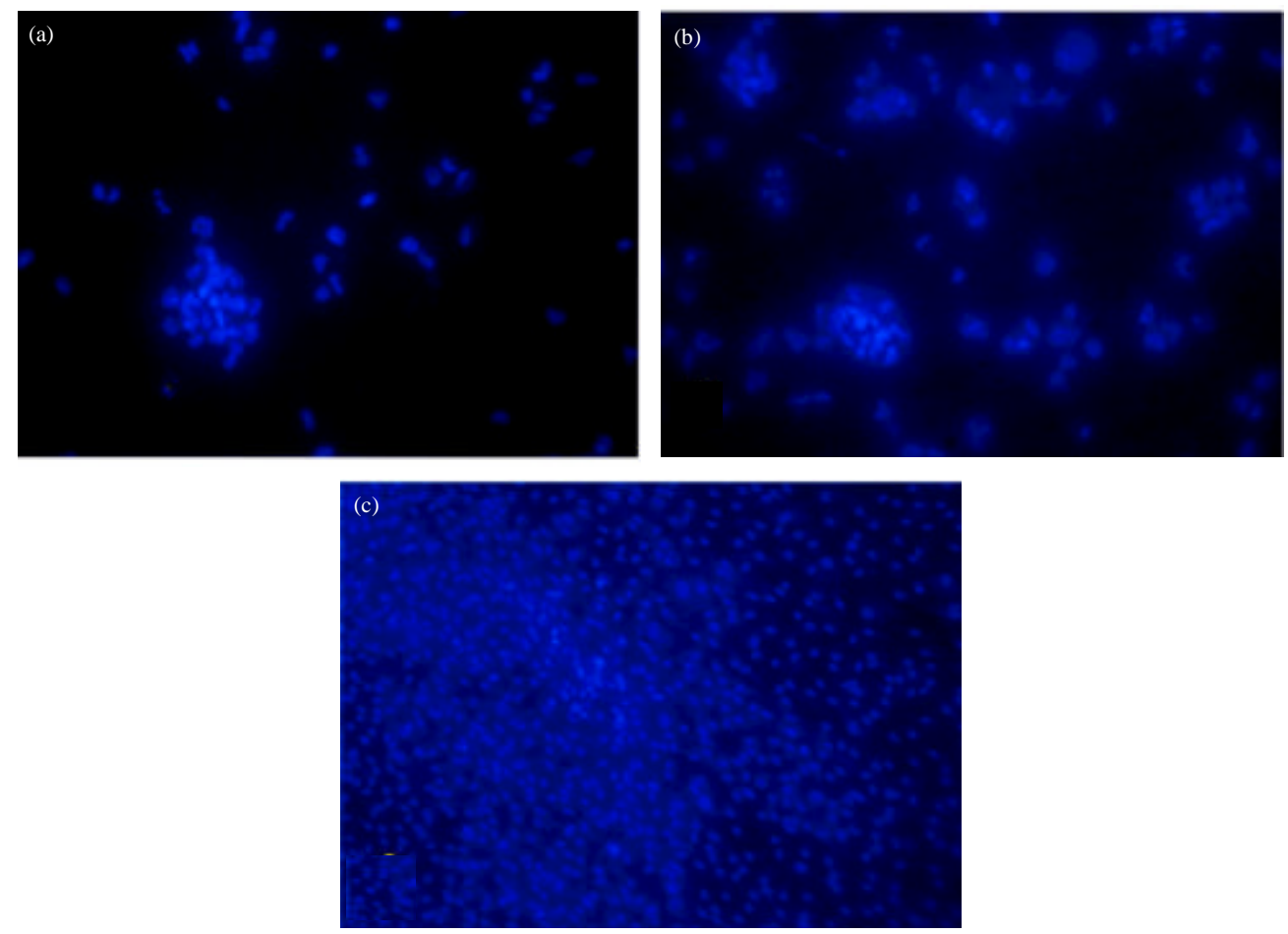

Fig. 4(a-c): Mesenchymal stem cells cultured on the hydroxyapatite scaffolds prepared by (a) Alkaline hydrothermal, (b) Aqueous hydrothermal (PLPW) and (c) Thermal process. The cells were stained by DAPI and observed by a fluorescence microscope. The proliferation and viability was more in the cells grow on the hydroxyapatite scaffolds prepared by thermal process. The magnification for $\mathrm{A}$ and $\mathrm{B}$ is $200 \mathrm{x}$ and for $\mathrm{C}$ is $100 \mathrm{x}$ 

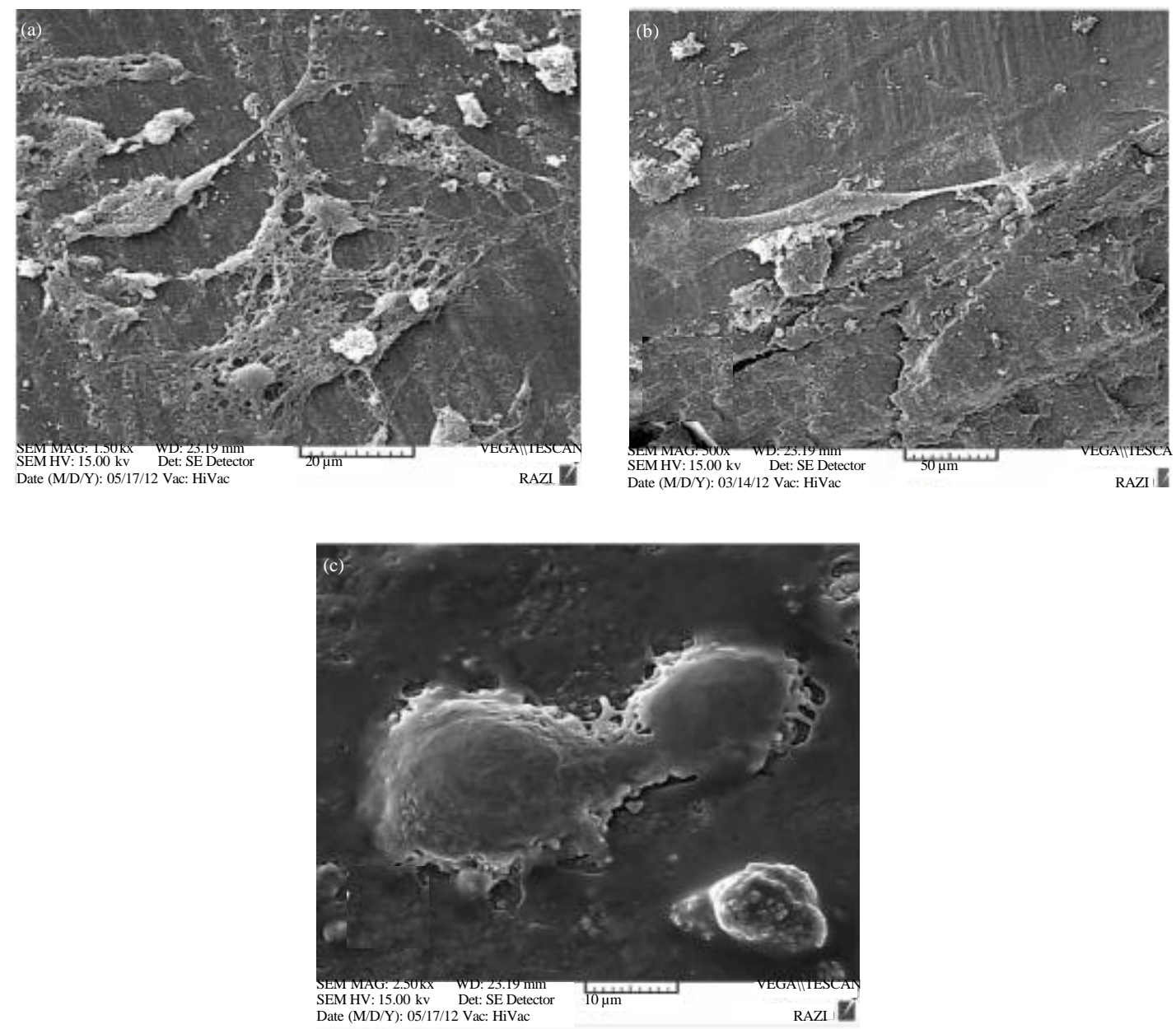

Fig. 5(a-c): Scanning electron microscopy of the mesenchymal stem cells cultured on the hydroxyapatite scaffolds prepared by (a) Alkaline hydrothermal, (b) Aqueous hydrothermal (PLPW) and (c) Thermal process

respectively. The cells did not express CD 144 and CD34. The observations from DAPI staining showed the cells could attach on all scaffolds and they were not toxic for MSCs; however, the cell population was shown difference in number. The number of cells cultured on the scaffold prepared by thermal process was more populated than the other cultures (Fig. 4). Ultrastructural observations showed the morphology was also different in the cells grow on the scaffold prepared by thermal process. These cells had a round-shape morphology (Fig. 5c) while the cells were cultured on the scaffolds prepared by alkaline hydrothermal and aqueous hydrothermal (PLPW) expanded and had a satellite-shape morphology (Fig. 5a, b).

\section{CONCLUSION}

Several conclusions are taken from the study. The main ones are:

- The FT-IR results show that all of the thermal calcination, aqueous hydrothermal and alkaline hydrothermal processes have the ability of leaving CHAp

- This comparison suggests that all three utilized methods for extraction of carbonated hydroxyapatite from raw bovine bone are suitable and in cost

- Carbonated hydroxyapatite obtained by PLPW process, leaving more carbonate contents and preferable for medical application 
- The results of FT-IR analysis show that carbonate groups (A and $\mathrm{B}$ ) in thermal calcination are stable to $700^{\circ} \mathrm{C}$ and by increasing of operation temperature, its proportion decreases

- The cells could grow in all scaffolds; however, the survival was higher in the cells cultured on the thermal HCAp

\section{ACKNOWLEDGMENTS}

This study supported by Yazd Science and Technology Park (YSTP) and Eghbal Innovation Center. The authors would like to thank for their wise financial supports. Also, we would like to thank from Mrs. Salmannezhad and Mrs. Sani for their excellence technical supports in Laboratory for Stem Cell Research of Shiraz University of Medical Sciences (SUMS).

\section{REFERENCES}

1. Boccaccini, A.R. and J.E. Gough, 2007. Tissue Engineering Using Ceramics and Polymers. Woodhead Publishing Ltd., England, UK., ISBN-13: 9781845691769, Pages: 624.

2. Finkemeier, C.G., 2002. Bone grafting and bone graft substitutes. J. Bone Joint Surg. Am., 84: 454-464.

3. Murugan, R. and S. Ramakrishna, 2005. Development of nanocomposites for bone grafting. Comp. Sci. Technol., 65: 2385-2406.

4. Ben-Nissan, B., 2007. Natural bioceramics: From coral to bone and beyond. Curr. Opin. Solid State Mater. Sci., 7: 283-288.

5. Best, S.M., A.E. Porter, E.S. Thian and J. Huang, 2008. Bioceramics: Past, present and for the future. J. Eur. Ceram. Soc., 28: 1319-1327.

6. Thamaraiselvi, T.V., K. Prabakaran and S. Rajeswari, 2006. Synthesis of hydroxyapatite that mimic bone mineralogy. Trends Biomater. Artif. Organs, 19: 81-83.

7. Barrere, F., C.A. Van Blitterswijk and K. De Groot, 2006. Bone regeneration: Molecular and cellular interactions with calcium phosphate ceramics. Int. J. Nanomed., 1: 317-332.

8. Guizzardi, S., C. Montanari, S. Migliaccio, R. Strocchi, R. Solmi, D. Martini and A. Ruggeri, 2000. Qualitative assessment of natural apatite in vitro and in vivo. J. Biomed. Mater. Res., 53: 227-234.

9. Landi, E., G. Celotti, G. Logroscino and A. Tampieri, 2003. Carbonated hydroxyapatite as bone substitute. J. Eur. Ceram. Soc., 23: 2931-2937.

10. Joschek, S., B. Nies, R. Krotz and A. Gopferich, 2000. Chemical and physicochemical characterization of porous hydroxyapatite ceramics made of natural bone. Biomaterials, 21: 1645-1658.

11. Murugan, R., S. Ramakrishna and K.P. Rao, 2006. Nanoporous hydroxyl-carbonate apatite scaffold made of natural bone. Mater. Lett., 60: 2844-2847.
12. Haberko, K., M.M. Bucko, J. Brzezinska-Miecznik, M. Haberko and W. Mozgawa et al, 2006. Natural hydroxyapatite-its behaviour during heat treatment. J. Eur. Ceram. Soc., 26: 537-542.

13. Murugan, R., K.P. Rao and T.S. Kumar, 2003. Heat-deproteinated xenogeneic bone from slaughterhouse waste: Physico-chemical properties. Bull. Mater. Sci., 26: 523-528.

14. Ooi, C.Y., M. Hamdi and S. Ramesh, 2007. Properties of hydroxyapatite produced by annealing of bovine bone. Ceram. Int., 33: 1171-1177.

15. Barakat, N.A.M., M.S. Khil, A.M. Omran, F.A. Sheikh, H.Y. Kim, 2009. Extraction of pure natural hydroxyapatite from the bovine bones bio waste by three different methods. J. Mater. Proc. Technol., 209: 3408-3415.

16. Figueiredo, M., A. Fernando, G. Martins, J. Freitas, F. Judas and H. Figueiredo, 2010. Effect of the calcination temperature on the composition and microstructure of hydroxyapatite derived from human and animal bone. Ceram. Int., 36: 2383-2393.

17. Shakesheff, K. and G. Tsourapas, 2007. Surface Modification to Tailor the Biological Response. In: Tissue Engineering using Ceramics and Polymers, Boccaccini, A.R. and J.E. Gough (Eds.). Woodhead Publishing Ltd., England, UK., ISBN-13: 9781845691769, pp: 108.

18. Barrere, F., T.A. Mahmood, K. De Groot and C.A. Van Blitterswijk, 2008. Advanced biomaterials for skeletal tissue regeneration: Instructive and smart functions. Mater. Sci. Eng. R: Rep., 59: 38-71.

19. Malgieri, A., E. Kantzari, M.P. Patrizi and S. Gambardella, 2010. Bone marrow and umbilical cord blood human mesenchymal stem cells: State of the art. Int. J. Clin. Exp. Med., 3: 248-269.

20. Prien, E.L. and C. Frondel, 1947. Studies in urolithiasis: The composition of urinary calculi. J. Urol., 57: 949-994.

21. Fleet, M.E. and X. Liu, 2007. Coupled substitution of type A and B carbonate in sodium-bearing apatite. Biomaterials, 28: 916-926.

22. Pang, Y.X. and X. Bao, 2003. Influence of temperature, ripening time and calcination on the morphology and crystallinity of hydroxyapatite nanoparticles. J. Eur. Ceram. Soc., 23: 1697-1704.

23. Barakat, N.A.M., K.A. Khalil, F.A. Sheikh, A.M. Omran, B. Gaihre, S.M. Khil, H.Y. Kim, 2008. Physiochemical characterizations of hydroxyapatite extracted from bovine bones by three different methods: Extraction of biologically desirable Hap. Mater. Sci. Eng., 28: 1381-1387. 